\title{
Interspecific competition between Drosophila melanogaster and Drosophila simulans: temperature effect on competitive ability and fitness components
}

\author{
Catherine MONTCHAMP-MOREAU \\ Laboratoire de Génétique des Populations*, \\ Université Paris VII, 2, place Jussieu, F 75005 Paris
}

\begin{abstract}
Summary
Previous studies of laboratory and natural populations suggest that Drosophila simulans is much more restricted in its tolerance to different temperatures than its sibling species Drosophila melanogaster. We have studied competition between these two species in population cages at $20^{\circ} \mathrm{C}$, the optimal temperature for $D$. simulans, and at $25^{\circ} \mathrm{C}$ which seems to be more favourable to $D$. melanogaster. At $25^{\circ} \mathrm{C} D$. melanogaster eliminated $D$. simulans, but at $20^{\circ} \mathrm{C}$, the reverse occured. The temperature effect, on each of the three fitness components (fertility, larval viability and developmental time) measured in both species, in the experimental conditions of the cages, is in agreement with the observed outcome of interspecific competition.
\end{abstract}

Key-words: Drosophila melanogaster, Drosophila simulans, interspecific competition, temperature.

\section{Résumé}

Compétition entre Drosophila melanogaster et Drosophila simulans : Effet de la température sur leur compétitivité et sur diverses composantes de la valeur adaptative

Les données accumulées à ce jour, tant en laboratoire que dans la nature, montrent que la zone de tolérance thermique de $D$. simulans est beaucoup plus étroite que celle de son espèce jumelle $D$. melanogaster. Nous avons donc décidé d'étudier la compétition entre ces deux espèces dans des cages à population placées à des températures différentes : d'une part à $20^{\circ} \mathrm{C}$ qui est l'optimum thermique de $D$. simulans, d'autre part à $25^{\circ} \mathrm{C}$, température qui apparaît plus favorable à $D$. melanogaster qu'à $D$. simulans. A $25^{\circ} \mathrm{C}, D$. melanogaster élimina $D$. simulans, mais à $20^{\circ} \mathrm{C}$ l'inverse se produisit. Trois composantes de la valeur adaptative (fertilité, viabilité larvaire, temps de développement) ont été mesurées sur les populations des cages; les modifications de chacune de ces trois composantes, lorsque l'on passe de $20^{\circ} \mathrm{C}$ à $25^{\circ} \mathrm{C}$, sont en accord avec le résultat de la compétition interspécifique.

Mots-clés : Drosophila melanogaster, Drosophila simulans, compétition interspécifique, température.

\section{Introduction}

Temperature is one of the main ecological factors used to explain the differences between geographical and temporal distribution in nature of the two sibling species D. melanogaster and D. simulans.

Despite some differences between strains of the same species, due to their geographical origins, $D$. simulans is much more restricted in its tolerance to temperature than is $D$. melanogaster. In the laboratory, D. melanogaster has a physiological optimum at $21^{\circ} \mathrm{C}$ (DAVID \& CLAVEL, 1966; 1967), but grows well within a large range of temperature (from $15^{\circ} \mathrm{C}$ to $29.5^{\circ} \mathrm{C}$ ). On the other hand, $D$. simulans only grows well

(*) E.R.A. n 406 du C.N.R.S. : "Analyse et mécanismes de maintien du polymorphisme». 
around $20^{\circ} \mathrm{C}$ (Hosgood \& PARSONS, 1966). Mc KENZIE (1978) showed that maximum fecundity occured for $D$. simulans at $20^{\circ} \mathrm{C}$ and it was only at this temperature that $D$. simulans was found to be superior to D. melanogaster, the fecundity of which remained at an optimum between $15^{\circ} \mathrm{C}$ and $25^{\circ} \mathrm{C}$. Similar results were obtained for the emergence percentage (Mc KenzIE, 1978; TANTAWY \& MAllaH, 1961), and longevity (PARSONS, 1977; 1978).

These observations are in accordance with most of the geographical and seasonal distributions of these species: $D$. simulans outnumbers $D$. melanogaster in the regions where temperature fluctuations are small (PARSONS, 1975; ROCHA-PITE, 1980; KAWANISHI \& WATANABE, 1977).

Paradoxically, most competition experiments and fitness measurements of these two species have only been carried out at $25^{\circ} \mathrm{C}$. At this temperature, in population cages, when wild strains are used, $D$. melanogaster eliminated $D$. simulans. Yet, opposite results were observed with mutant strains (GOLDSTEIN \& TEISSIER, 1953) or with strains selected for their competitive ability (PARSONS, 1975 for a review; HEDRICK \& MURRAY, 1980). By contrast, MoOre (1952), then TANTAWY \& Soliman (1967) showed that at $15^{\circ} \mathrm{C} D$. simulans rapidly outnumbered $D$. melanogaster, although the latter species was not eliminated when the experiment stopped.

As the optimal temperature for $D$. simulans is near $20^{\circ} \mathrm{C}$, it was of interest (suggested by PARSONS, 1975) to study competition between the two species at this temperature. This paper first presents the results of the competition in population cages at $20^{\circ} \mathrm{C}$ and $25^{\circ} \mathrm{C}$. In addition to observing changes in the frequencies of the two species at these temperatures, observations were also made on three fitness components, namely fertility, larval viability and developmental time, measured in the experimental conditions of the cages.

\section{Materials and Methods}

\section{A. Populations in competition}

The two french wild strains used in this study, D. melanogaster Chevreuse $(\mathrm{mel}+)$ and $D$. simulans Villeurbanne $(\operatorname{sim}+)$, had been collected in the wild two years before the experiment commenced. Ten population cages $(10 \times 15 \times 40 \mathrm{~cm})$ were initiated with 1000 adults ( 500 males and 500 females). Five cages were maintained at $20^{\circ} \mathrm{C}$ and five at $25^{\circ} \mathrm{C}$. At $20^{\circ} \mathrm{C}$, the initial frequency of each species was 0.5 . At $25^{\circ} \mathrm{C}$ the initial frequencies were 0.2 for $D$. melanogaster and 0.8 for $D$. simulans, to avoid the too rapid elimination of the latter species. At both $20^{\circ} \mathrm{C}$ and $25^{\circ} \mathrm{C}$, two cages contained only the wild strains of the two species. In the other three cages, different morphological polymorphisms were introduced, namely vermilion (v), sepia (se) and cinnabar (cn), in order to observe the effect of these polymorphisms on the interspecific competition. The mutant stocks used had been kept under laboratory conditions for many years. The composition of the cages and the system used to designate them is summarized in Table 1. The initial frequency of the mutants was 0.8 .

The populations were maintained in overlapping generations by supplying each cage with two cups of fresh medium (PEARL et al., 1926) every two days. The cages at $20^{\circ} \mathrm{C}$ contained 24 cups and each cup stayed in the cage for 24 days. The cages at $25^{\circ} \mathrm{C}$ contained 18 cups, each of them remaining there 18 days.

Under these experimental conditions there was strong competition among the larvae for food. The number of adults in the cages averaged 2000 over the period of the observation. At $20^{\circ} \mathrm{C}$, this number was very stable but at $25^{\circ} \mathrm{C}$, great fluctuations occured. 
TABLE 1

Initial composition of the ten populations (see text).

Composition initiale des dix populations (voir le texte).

\begin{tabular}{l|c|c|c|c|c|c|c|c|c|c}
\hline & \multicolumn{9}{|c|}{$20^{\circ} \mathrm{C}$} & \multicolumn{6}{c}{$25^{\circ} \mathrm{C}$} \\
\cline { 2 - 9 } $\mathrm{n}^{\circ}$ cage & $\mathrm{S} 1$ & $\mathrm{~S} 1$ & $\mathrm{~S} 2$ & $\mathrm{~S} 3$ & $\mathrm{~S} 4$ & $\mathrm{M} 1$ & $\mathrm{M}^{\prime} 1$ & $\mathrm{M} 2$ & $\mathrm{M} 3$ & $\mathrm{M} 4$ \\
mel & + & + & $+; v$ & $+; c n$ & $+; s e$ & + & + & $+; v$ & $+; c n$ & $+; s e$ \\
sim & + & + & $+; v$ & $+; v$ & $+; s e$ & + & + & $+; v$ & $+; v$ & $+; s e$ \\
\hline
\end{tabular}

(v: vermilion, se: sepia, cn: cinnabar)

Changes in the relative frequencies of the two species were measured by periodic egg samples. Two food cups were placed in each cage and left for 24 hours. They were then allowed to develop without any additional supply of medium so that larval competition was the same as in the cages. When adults emerged, the males (between 100 to 150 ) were all classified and counted.

\section{B. Fitness components}

Three components of fitness were measured, fertility, larval viability and time of development. These are known to show great variation, depending on environmental conditions, in particular larval density, adult number and species frequencies (PARSONS, 1975 for a review). Consequently, these measurements were made directly on the cages flies in order to reflect as exactly as possible what occurred during evolution of the populations. Fertility and developmental time were measured only in the cages containing wild populations, and larval viability in all cages.

\section{1) Fertility}

Fertility at $20^{\circ} \mathrm{C}$ was measured in cage $\mathrm{S}^{\prime} 1$, and fertility at $25^{\circ} \mathrm{C}$ in cage $\mathrm{M}^{\prime} 1$. A sample of about 200 adults was taken from the cages, at four different times (samples 1 to 4). Each female was put into a vial with $20 \mathrm{ml}$ of medium so that the surface avaible for oviposition was the same as that in the cages, but there was no competition for food among the larvae. The females were allowed to lay eggs for 24 hours and then they were put back into the cages.

The adults that emerged were all counted and their species determined. The fertility of each species was measured as the mean number of offspring produced by one productive female.

\section{2) Larval to adult viability}

Three cups of food were periodically introduced into each cage. Two of them were allowed to develop without any new supply of medium, so that larval competition for food was the same as in the cages (crowded series : CS). The third cup was evenly distributed between two bottles with a supply of food, in order to reduce larval competition (uncrowded series : USC).

The differences in the frequencies of adults of each species emerging from these two series (CS and UCS) were due to larval competition.

\section{3) Developmental time}

Two cups of food were introduced into the cages for 24 hours. They were then removed and each day the number of emerging males was counted. 


\section{Results and Discussion}

\section{A. Population evolution}

Changes in the frequencies of $D$. simulans in each of the ten cages are shown in Fig. 1. At $25^{\circ} \mathrm{C}, D$. simulans was eliminated by $D$. melanogaster in all five cages; a result which agrees with previous findings. At $20^{\circ} \mathrm{C}$ the opposite result occurred with D. melanogaster always being eliminated.

Introducing homologous mutants (sepia or vermilion) into the wild strains of the two species does not change the outcome of competition. Each of these mutations certainly had a similar influence, in both species, on the competitive ability of the populations into which it has been introduced. In fact, it was established that both sepia and vermilion genes respectively reached the same stable balance with the wild type in both species (MONTCHAMP-MOREAU, 1982).
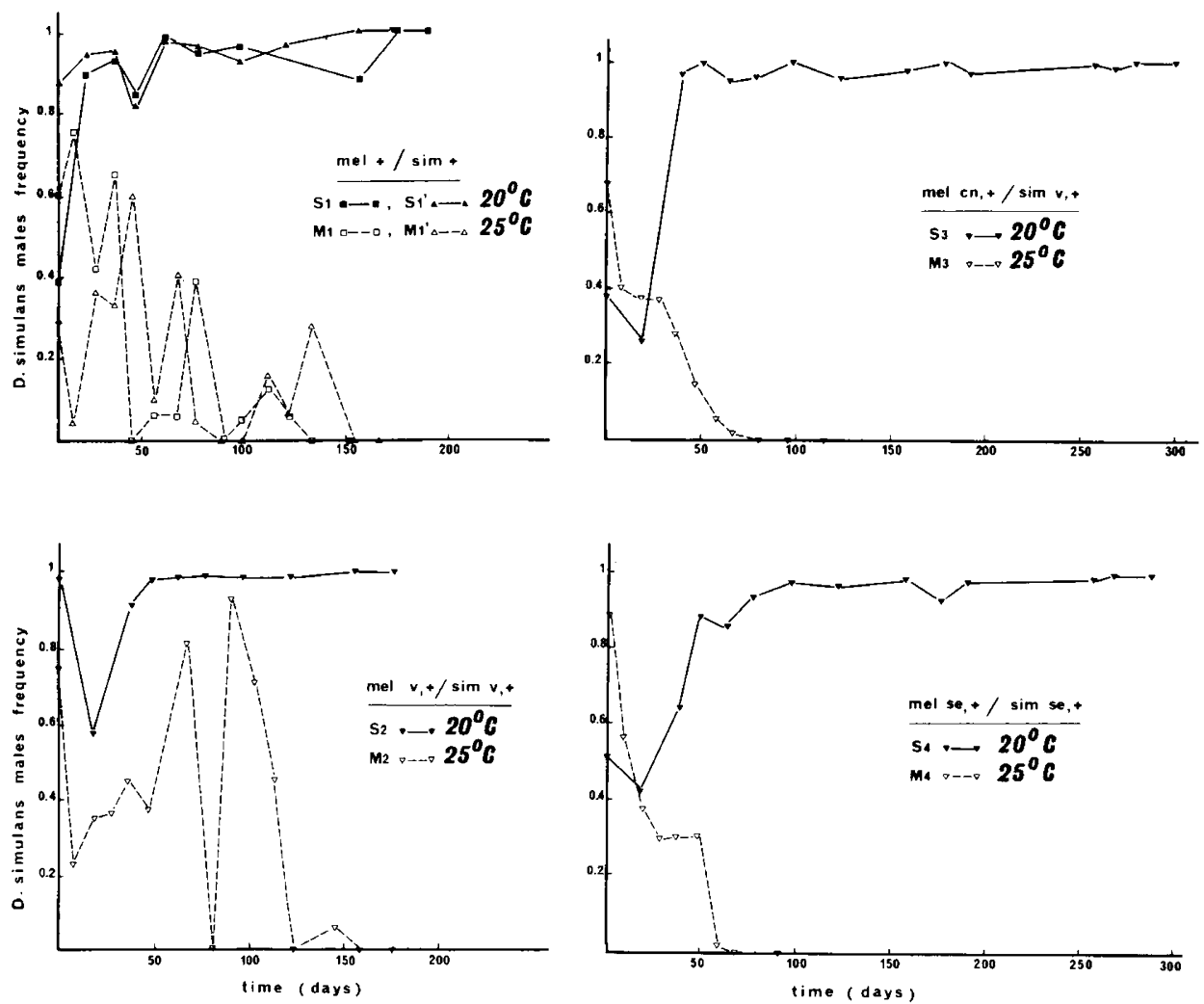

FIG. 1

Competition between D. simulans and D. melanogaster: evolution of D. simulans frequency (among the males) in the ten population cages.

Compétition entre $\mathrm{D}$. simulans et $\mathrm{D}$. melanogaster : évolution de la fréquence de $\mathrm{D}$. simulans (mesurée chez les mâles) dans les dix cages à population. 
The elimination rates of a species did not differ greatly between the two identical cages of wild populations: there was a difference of 19 days for $D$. melanogaster elimination between cages $S 1$ and $S^{\prime} 1$ and a difference of 22 days for $D$. simulans elimination between cages $\mathrm{M} 1$ and $\mathrm{M}^{\prime} 1$.

In contrast, comparison of elimination rates for each species in homologous cages at $20^{\circ} \mathrm{C}$ and $25^{\circ} \mathrm{C}$ (Table 1) shows that these rates were certainly modulated by differences in competitive ability among the strains. For example, the wild/sepia population of $D$. simulans, which was the most rapidly eliminated at $25^{\circ} \mathrm{C}$ ( 68 days), was the slowest to eliminate $D$. melanogaster at $20^{\circ} \mathrm{C}$ ( 267 days). These differences in competitive ability among the populations of the cages are certainly due to differences in the genetic background of the mutant strains.

TABLE 2

Elimination delays (in days) of D. melanogaster $\left(\right.$ at $20^{\circ} \mathrm{C}$ ) and of D. simulans (at $\left.25^{\circ} \mathrm{C}\right)$ in the ten population cages.

Délais d'élimination (en jours) de D. melanogaster $\left(\grave{a} 20^{\circ} \mathrm{C}\right.$ ) et de D. simulans $\left(\grave{a} 25^{\circ} \mathrm{C}\right)$ dans les dix cages à population.

\begin{tabular}{|c|c|c|c|c|}
\hline $\begin{array}{l}\text { Population } \\
\text { composition }\end{array}$ & $\begin{array}{l}\text { mel + } \\
\text { sim + }\end{array}$ & $\begin{array}{l}\text { mel v; }+ \\
\operatorname{sim} v ;+\end{array}$ & $\begin{array}{c}\text { mel cn; }+ \\
\operatorname{sim} v ;+\end{array}$ & $\begin{array}{l}\text { mel se; }+ \\
\text { sim se; }+\end{array}$ \\
\hline $\begin{array}{l}\text { Elimination } \\
\text { delay of } \\
D . \text { melanogaster } \\
\text { at } 20^{\circ} \mathrm{C}\end{array}$ & $\begin{array}{l}176 \\
157\end{array}$ & 157 & 288 & 267 \\
\hline $\begin{array}{l}\text { Elimination } \\
\text { delay of } \\
D . \text { simulans } \\
\text { at } 25^{\circ} \mathrm{C}\end{array}$ & $\begin{array}{l}147 \\
125\end{array}$ & 160 & 68 & 68 \\
\hline
\end{tabular}

\section{B. Fitness components}

\section{Fertility}

In all the samples, an appreciable proportion of females produced no offspring (unproductive females). The frequencies of each species among the productive females are not significantly different from the frequencies observed for the males in six of the eight samples (Table 3). In the two samples where a significant difference is observed, there is a shortage of $D$. simulans among the productive females. MOTH (1974) obtained similar results. He showed that when adult density is high, the percentage of unfertile females is much higher in $D$. simulans than in $D$. melanogaster. But it must be pointed out that our experimental conditions (isolated females) suppressed the effect of intra and interspecific competition for oviposition sites, which seems to be particularly important in reducing oviposition in D. melanogaster (FUTUYMA, 1970; SAMEOTO \& MILlER, 1966). Thus, our results must be regarded with caution.

Results for productive females are given in Table 4. For each species and each temperature, mean fertilities are significantly different in the four samples, except for D. simulans at $20^{\circ} \mathrm{C}$. Such changes in fertility during the course of the competition might be due to environmental fluctuations and to variations of age structure in the adult population. 
TABLE 3

D. simulans frequency among males and productive females, and improductive females frequency in each adult sample from cages containing the wild populations ( $S^{\prime} 1$ at $20^{\circ} \mathrm{C}$ and $M^{\prime} 1$ at $25^{\circ} \mathrm{C}$ ).

Fréquence de D. simulans parmi les mâles et parmi les femelles productives, fréquence des femelles productives dans chaque échantillon d'adultes extrait des cages contenant les populations sauvages $\left(S^{\prime} 1\right.$ à $20^{\circ} \mathrm{C}$ et $M^{\prime} 1$ à $25^{\circ} \mathrm{C}$ ).

\begin{tabular}{|c|c|c|c|c|c|c|c|c|c|}
\hline & \multirow{2}{*}{$n^{\circ}$ sample } & \multicolumn{3}{|c|}{ males } & \multicolumn{3}{|c|}{ productive females } & \multirow{2}{*}{$\varepsilon$} & \multirow{2}{*}{$\begin{array}{l}\text { improductive } \\
\text { females } \\
\text { frequency }\end{array}$} \\
\hline & & tot. & $\operatorname{sim}$. & freq. & tot. & $\operatorname{sim}$. & freq. & & \\
\hline $20^{\circ} \mathrm{C}$ cage & $\begin{array}{l}1 \\
2 \\
3 \\
4\end{array}$ & $\begin{array}{l}134 \\
103 \\
144 \\
190\end{array}$ & $\begin{array}{r}98 \\
81 \\
121 \\
183\end{array}$ & $\begin{array}{l}.731 \\
.786 \\
.840 \\
.963\end{array}$ & $\begin{array}{r}111 \\
80 \\
95 \\
68\end{array}$ & $\begin{array}{l}72 \\
58 \\
68 \\
62\end{array}$ & $\begin{array}{l}.649 \\
.725 \\
.716 \\
.912\end{array}$ & $\begin{array}{l}1.386 \\
.958 \\
2.307^{*} \\
1.656\end{array}$ & $\begin{array}{l}.24 \\
.58 \\
.43 \\
.49\end{array}$ \\
\hline $25^{\circ} \mathrm{C}$ cage & $\begin{array}{l}1 \\
2 \\
3 \\
4\end{array}$ & $\begin{array}{l}102 \\
158 \\
137 \\
170\end{array}$ & $\begin{array}{r}91 \\
111 \\
30 \\
16\end{array}$ & $\begin{array}{l}.892 \\
.703 \\
.219 \\
.094\end{array}$ & $\begin{array}{l}60 \\
66 \\
92 \\
97\end{array}$ & $\begin{array}{r}49 \\
27 \\
26 \\
6\end{array}$ & $\begin{array}{l}.817 \\
.409 \\
.283 \\
.062\end{array}$ & $\begin{array}{l}1.350 \\
4.124^{*} \\
1.104 \\
.917\end{array}$ & $\begin{array}{l}.43 \\
.46 \\
.26 \\
.28\end{array}$ \\
\hline
\end{tabular}

* significant $(0.05)$

TABLE 4

Mean fertilities of D. simulans ( $F$ sim) and D. melanogaster ( $F$ mel) and relative fertilities of D. melanogaster $\left(\frac{F \text { mel }}{F \text { sim }}\right)$ at $20^{\circ} \mathrm{C}$ (cage $\left.S^{\prime} 1\right)$ and $25^{\circ} \mathrm{C}$ (cage $M^{\prime} 1$ ).

Fertilités moyennes de D. simulans $(F$ sim) et D. melanogaster ( $F$ mel) et fertilités relatives de D. melanogaster $\left(\frac{F \text { mel }}{F \text { sim }}\right)$ à $20^{\circ} \mathrm{C}$ (cage $\left.S^{\prime} 1\right)$ et $25^{\circ} \mathrm{C}$ (cage M'1).

\begin{tabular}{|c|c|c|c|c|c|c|c|c|}
\hline \multirow[b]{2}{*}{ Samples } & \multicolumn{4}{|c|}{$20^{\circ} \mathrm{C}$ cage } & \multicolumn{4}{|c|}{$25^{\circ} \mathrm{C}$ cage } \\
\hline & 1 & 2 & 3 & 4 & 1 & 2 & 3 & 4 \\
\hline $\begin{array}{l}\text { F mel } \\
\pm 2 \sigma \\
F \operatorname{sim} \\
\pm 2 \sigma\end{array}$ & $\begin{array}{r}13.6 \\
3.0 \\
6.2 \\
1.0\end{array}$ & $\begin{array}{r}19.8 \\
4.6 \\
6.5 \\
2.6\end{array}$ & $\begin{array}{r}14.5 \\
3.3 \\
7.2 \\
2.0\end{array}$ & $\begin{array}{l}9.8 \\
5.7 \\
9.8 \\
2.4\end{array}$ & $\begin{array}{r}24.3 \\
6.5 \\
13.6 \\
3.3\end{array}$ & $\begin{array}{r}31.9 \\
4.2 \\
14.0 \\
5.8\end{array}$ & $\begin{array}{r}24.6 \\
2.8 \\
4.3 \\
1.0\end{array}$ & $\begin{array}{r}30.8 \\
2.6 \\
9.8 \\
7.3\end{array}$ \\
\hline$\frac{F \text { mel }}{F \operatorname{sim}}$ & 2.2 & 3.0 & 2.0 & 1.0 & 1.8 & 2.3 & 5.7 & 3.1 \\
\hline U obs & $4.28 *$ & $5.07^{*}$ & $3.79 *$ & 0.02 & $2.92 *$ & $4.98^{*}$ & $13.55^{*}$ & $5.41^{*}$ \\
\hline
\end{tabular}

$\pm 2 \sigma=5 \%$ confidence interval of $F$ significant $(0.05)$

On the other hand, they might be a response to selection for competitive ability induced by the interspecific and intra specific competition (AIKEN \& GIBO, 1979).

At $20^{\circ} \mathrm{C}, D$. melanogaster fertility is significantly higher than $D$. simulans fertility in three of the four samples. At $25^{\circ} \mathrm{C}, \mathrm{D}$. melanogaster fertility is significantly higher in all four samples. A statistical comparison of the fertility of each species at the two temperatures could not be made, since the results are heterogeneous and the number of samples is too small at each temperature. Nevertheless, the relative fertility of $D$. melanogaster ( $D$. melanogaster fertility/D. simulans fertility) seems slightly greater at $25^{\circ} \mathrm{C}$ than at $20^{\circ} \mathrm{C}$. 


\section{Larval to adult viability}

The effects of larval competition on pre-adult viability were analysed by comparing the relative frequency of each species among the males which emerged from uncrowded and crowded series (fig. 2).

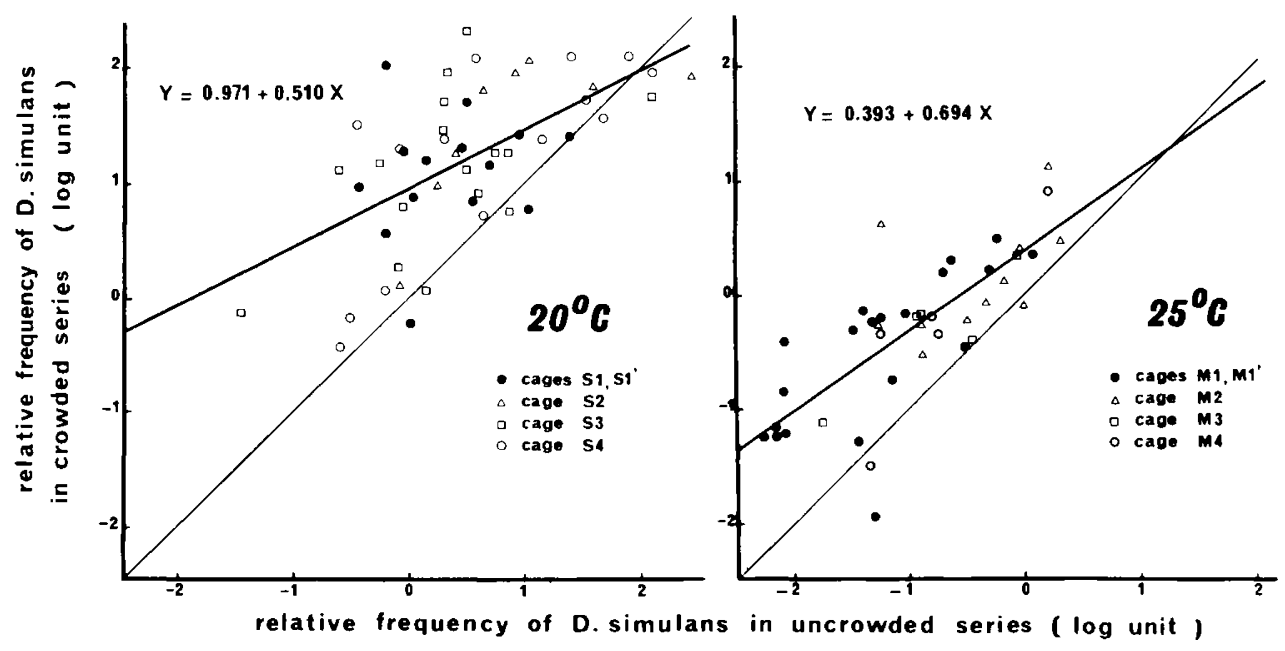

FIG. 2

Competition effect on the larval to adult viability: linear regression of the logarithmic ratios of D. simulans to D. melanogaster frequencies in the crowded series on the corresponding logarithmic ratios in uncrowded series.

Effet de la compétition sur la viabilité larvo-nymphale: régression linéaire des rapports des fréquences de D. simulans à celles de D. melanogaster entre les séries avec concurrence et les séries sans concurrence.

The ratio of frequencies of each species (expressed as the number of simulans males: the number of melanogaster males) for the crowded series (CS) was plotted against the similar ratio for the corresponding uncrowded series (UCS). On such a diagram, the experimental points falling below the line drawn at $45^{\circ}$ through the origin indicate that $D$. melanogaster,was at an advantage in larval competition for food. The points located above indicate an advantage to $D$. simulans.

At $20^{\circ} \mathrm{C}$ and $25^{\circ} \mathrm{C}$, the frequency of $D$. simulans was either significantly higher in the crowded series than in the uncrowded series ( 30 times out of 56 at $25^{\circ} \mathrm{C}, 30$ times out of 66 at $20^{\circ} \mathrm{C}$ ), or the differences were not significant. Thus, larval competition in the experimental conditions of our population cages favoured $D$. simulans.

At both temperatures, the regression coefficients are significantly lower than one, so that the effects of interspecific larval competition could be considered as frequency dependent. The slopes of the regression lines at $20^{\circ} \mathrm{C}$ and $25^{\circ} \mathrm{C}$ are not significantly different $(t=1.35 ; 99 \mathrm{df})$, so that the frequency dependent effect is the same at the two temperatures. But at $20^{\circ} \mathrm{C}$, the ordinate at the origin is significantly higher than at $25^{\circ} \mathrm{C}\left(5 \%\right.$ confidence interval at $20^{\circ} \mathrm{C}: 0.16-0.62$, at $\left.25^{\circ} \mathrm{C}: 0.79-1.15\right)$, so that $D$. simulans is at a greater advantage at $20^{\circ} \mathrm{C}$ than at $25^{\circ} \mathrm{C}$. The two regression lines suggest that $D$. melanogaster would be at an advantage only when at very low frequency in the larval population $\left(0.05\right.$ at $25^{\circ} \mathrm{C}, 0.01$ at $\left.20^{\circ} \mathrm{C}\right)$. However, we cannot affirm that such an advantage really occurs. 
These results cannot be easily compared with previous studies on larval competition (Miller, 1964; Tantawy \& Soliman, 1967; Barker \& Podger, 1970; Wallace, 1974), since in our case, the larval density is high but not controlled. In fact, when density is high, even with controlled conditions, results are of ten not repeatable because of micro-environmental variations; especially important ecological interactions were shown to exist between Drosophila and yeast populations (SANG et al., 1949; ERK \& SANG, 1966; El HELW \& ALI, 1970). In the present study where neither the larval density nor the micro-environment was controlled, we observed wide variations in ratios in the crowded series, for very similar ratios in uncrowded series.

\section{Time of development (fig. 3)}

This was measured when the species frequencies in the cages were 0.75 simulans and 0.25 melanogaster.

At $25^{\circ} \mathrm{C}$, the emergence occurred in both species between 8 and 18 days after oviposition. On average, $D$. melanogaster developed faster, with a mean developmental time of $11.61 \pm 0.28$ days for $D$. melanogaster males $(n=320)$ and $12.18 \pm 0.20$ days for D. simulans males $(\mathrm{n}=493)$.

At $20^{\circ} \mathrm{C}$, emergences occured from day 13 to day 28 for $D$. simulans males and their mean developmental time was $18.40 \pm 0.30$ days $(n=437)$ D. melanogaster males developed more slowly. They emerged from day 14 to day 28 and their mean developmental time was $20.02 \pm 0.42$ days $(n=261)$. The influence of species frequencies upon developmental time was not studied here, but it has been shown to exist (BARKER \& PODGER, 1970).
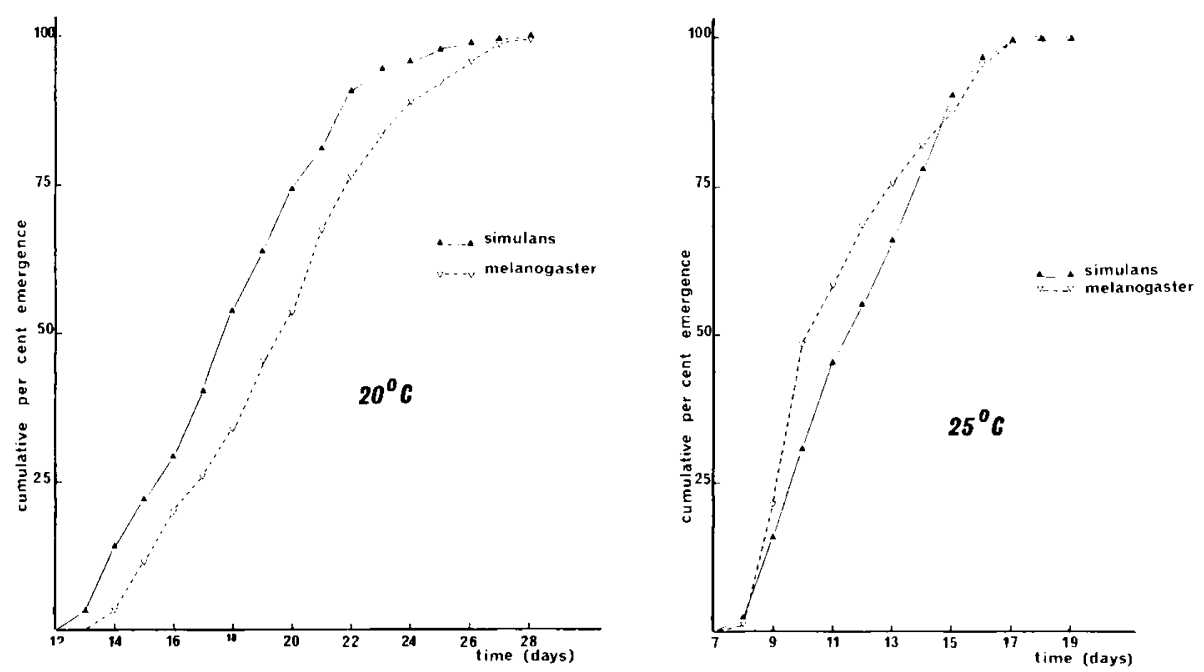

FIG. 3

Developmental time of D. melanogaster and D. simulans in the cages experimental conditions: cumulative distributions (in \%) of daily emergences from the oviposition day.

Temps de développement de $\mathrm{D}$. melanogaster et $\mathrm{D}$. simulans dans les conditions expérimentales des cages : distributions cumulées (en \%) des émergences quotidiennes à partir du jour de ponte. 


\section{Conclusion}

Previous studies on fecundity, viability, longevity showed that $20^{\circ} \mathrm{C}$ was the most favourable temperature for $D$. simulans. The present results show that, at this temperature, and when high competition for food occurs, this species shows itself to be at a great advantage over $D$. melanogaster, since the latter species is eliminated in all five cages. The most rapid elimination occurs after 157 days (in cage $S^{\prime} 1$ and S2), the slowest after 288 days (in cage S3). At $15^{\circ}$ C, Moore (1952), TanTawy \& Soliman (1967) did not observe the elimination of $D$. melanogaster which was still maintaining itself at a low frequency when their experiments stopped (respectively after 800 and 340 days of competition). One could argue that a comparison of our results with these of the three previous authors is avoided because of differences between the strains used or between experimental conditions. But all these results in population cage experiments at $15^{\circ} \mathrm{C}$ and $20^{\circ} \mathrm{C}$ are in accordance with the numerous studies of the temperature effect on fitness components. So we can conclude that $D$. simulans is more successful against D. melanogaster at $20^{\circ} \mathrm{C}$ than at $15^{\circ} \mathrm{C}$. It would now be interesting to know the width of this thermal zone of superiority of $D$. simulans and whether it is continuous from $20^{\circ} \mathrm{C}$ to $15^{\circ} \mathrm{C}$. In order to answer this question we propose to undertake competition experiments at intermediate temperatures and also at $21^{\circ} \mathrm{C}$ which is the physiological optimum of D. melanogaster (DAVID \& ClAVEL, 1966; 1967).

Temperature has a differential effect on the three fitness components measured in the two species:

- D. melanogaster is at an advantage for fertility at both temperatures, but its advantage seems greater at $25^{\circ} \mathrm{C}$. The mean daily production of offspring of a D. melanogaster female is higher at $25^{\circ} \mathrm{C}$ than at $20^{\circ} \mathrm{C}$, but for $D$. simulans, the two fertilities are less different.

- Larval competition favours $D$. simulans at both temperatures, but its superiority over D. melanogaster is greater at $20^{\circ} \mathrm{C}$ than at $25^{\circ} \mathrm{C}$.

- D. simulans develops faster than D. melanogaster at $20^{\circ} \mathrm{C}$ but at $25^{\circ} \mathrm{C}$ the situation is reversed.

Changes of each of these three parameters with temperatures agree with the results of interspecific competition in the cages. They are likely to be the main which determine competitive success.

Larval selection may be a very important factor, since competition for food was extremely severe in the cages. On the other hand, selection experiments carried by TANTAWY et al. (1976) indicate that productivity is not a major factor in determining the outcome of competition between D. simulans and D. melanogaster. Yet, fertility, larval to adult viability and time of development must be considered as interdependant component. In fact, the situation described by BAKKER (1961) for interspecific competition may be extended to the interspecific level: in a larval population with severe competition for food, only the group of fast-growing larvae can reach the critical weight required for successful development before the food supply is exhausted. Hence, the greater advantage of $D$. simulans for larval viability and, consequently, its success at $20^{\circ} \mathrm{C}$, might be considered as the result of its developmental time being shorter than that of D. melanogaster. 


\section{References}

AIKEN R.B., GiBo D., 1979. Changes in fecundity of D. melanogaster and D. simulans in response to selection for competitive ability. Oecologia, (Berl.), 43, 63-77.

BAKKER K., 1961. An analysis of factors which determine success in competition for food among larvae of D. melanogaster. Arch. Neerl. Zool., 200-281.

BARKER J.S.K., PODGER R.N., 1970. Interspecific competition between D. melanogaster and $D$. simulans: effect of larval density on viability, developmental period and adult body weight. Ecology, 51, 170-189.

David J., Clavel M.F., 1966. Essai de définition d'une température optimale pour le développement de la drosophile. C.R. Acad. Sci. Paris, 262, 2159-2162.

David J., Clavel M.F., 1967. Influence de la température subie au cours du développement sur divers caractères biométriques des adultes de $D$. melanogaster. J. Insect Physiol., 13, 717-729.

ERK F.C., SANG J.H., 1966. The comparative nutritional requirements of the two sibling species D. simulans and D. melanogaster. J. Insect Physiol., 12, 43-51.

El Helw M.R., Ali A.M.M., 1970. Competition between D. melanogaster and D. simulans on media supplemented with Saccharomyces and Schizosaccharomyces. Evolution, 24, 531-537.

FutuYma D.J., 1970. Evolution of competition between D. melanogaster and D. simulans. Diss. Abstr. Int., Sect. B : Sci. Eng., 4425B-4426B.

GoldSTEIN L., Teissier G., 1953. Recherches sur les populations mixtes expérimentales de D. melanogaster et D. simulans. Proc. 9th Congr. Genet. Bellagio, 668-670.

Hedrick P.W., MurRay E., 1980. Competition between D. melanogaster and D. simulans from natural populations. Drosoph., Inf., Serv., 55, 58.

Hosgood J.M.W., PARSONS P.A., 1966. Differences between D. melanogaster and D. simulans in tolerance to laboratory temperatures. Drosoph., Inf., Serv., 41, 176.

KAWANISHi M., WatANABE T.K., 1977. Ecological factors controlling the coexistence of the sibling species D. simulans and D. melanogaster. Jap. J. Ecol., 27, 279-283.

MC KENZIE J.A., 1978. The effect of developmental temperature on population flexibility in D. melanogaster and D. simulans. Austr. J. Zool., 26, 105-112.

MC KENZIE J.A., 1964. Larval competition in D. melanogaster and D. simulans. Ecology, 45, 132-147.

MILLER R.S., 1964. Larval competition in D. melanogaster and D. simulans. Ecology, 45, 132-147.

MONTChAMP-MOREAU C., 1982. Comparaison du polymorphisme à des locus homologues dans les espèces jumelles $D$. melanogaster et $D$. simulans. Genetica, $59,145-150$.

MoORE J.A., 1952. Competition between D. melanogaster and D. simulans. I: Population cage experiments. Evolution, 6, 407-420.

Moтн J.J., 1974. Density, frequency and interspecific competition : fertility of $D$. simulans and D. melanogaster. Oecologia (Berl.), 14, 237-246.

PARSONS P.A., 1975. The comparative evolutionary biology of the sibling species D. melanogaster and D. simulans. Q. Rev. Biol., 50, 151-169.

PARSONS P.A., 1977. Genotype-temperature interaction for longevity in natural populations of D. simulans. Exp. Gerontol., 12, 241-244.

PARSONS P.A., 1978. The effect of genotype and temperature on longevity in natural populations of D. melanogaster. Exp. Gerontol., 13, 167-169.

Pearl R., Allan A.L., Penniman W.B.D., 1926. Culture media for Drosophila: a new medium and its influence on fertility at different densities of population. Am. Nat., 60, 357-366.

Rocha PITE M.T., 1980. Stratégies adaptatives et biologie des populations de drosophilides de quelques habitats typiques du Portugal. Thèse de Doctorat d'État. Paris.

SAMEOTo D.D., MilleR R.S., 1966. Factors controlling the productivity of $D$. melanogaster and D. simulans. Ecology, 47, 695-704.

SANG J.H., MC Donald J.M., GoRdon C., 1949. The ecological determinants of population growth in Drosophila culture. Physiol. Zool., 22, 210-223.

Tantawy A.O., Mallah G.S., 1961. Studies on natural populations of Drosophila. I. Heat resistance and geographical variations in D. melanogaster and D. simulans. Evolution, 15, 1-14.

Tantawy A.O., Soliman M.H., 1967. Studies on natural populations of Drosophila. VI. Competition between D. melanogaster and D. simulans. Evolution, 21, 34-40. 
Tantawy A.O., Mourad A.M., Dawood M.M., El-Dabbagh H., 19/6. Studies on natural populations of Drosophila. XVIII. Response to selection for high productivity in Drosophila melanogaster and Drosophila simulans and their interspecific competition. Egypt. J. Genet. Cytol., 5, 1-14.

Wallace B., 1974. Studies on intra and interspecific competition in Drosophila. Ecology, 55, 227-244. 